\title{
TELEVISÃO E INFÂNCIA: O QUE AS PROFESSORAS PENSAM SOBRE ESSE BINÔMIO
}

Jéssika Naiara da Silva, José Milton de Lima, Márcia Regina Canhoto de Lima, Leonardo de Angelo Orlandi

Universidade Estadual Paulista "Julio de Mesquita Filho", Programa de Pós Graduação em Educação, Presidente Prudente, SP. E-mail jessika 4@hotmail.com.

\section{RESUMO}

O artigo apresenta uma pesquisa realizada em uma pré-escola que teve como objetivo: verificar as interpretações que as professoras possuíam sobre a relação criança e televisão. No referencial teórico utilizou-se autores da Sociologia da Infância e Comunicação Social. O método de investigação foi do tipo etnográfico, utilizando-se como procedimento metodológico a observação participante e a entrevista semiestruturada, com o apoio de gravador. Os resultados indicam a necessidade de uma formação para os professores que contribua no processo de interlocução entre as culturas infantis que as crianças trazem e manifestam por meio de brincadeiras, diálogos, expressões e objetos no ambiente escolar.

Palavras-chave: Crianças; Culturas Infantis; Televisão; Professores.

\section{TELEVISION AND CHILDHOOD: WHAT TEACHERS THINK ABOUT THIS BINOMIO}

\begin{abstract}
The article presents a survey conducted in a pre-school that aimed to: verify the interpretations that the teachers had about the relationship children and television. In the theoretical framework we were used authors of the sociology of childhood and Media. The research method was ethnographic type, using as methodological procedure participant observation and semistructured interview with the recorder support. The results indicate the need for training for teachers to contribute in the dialogue process between the child cultures that children bring and manifest through play, dialogues, expressions and objects in the school environment.
\end{abstract}

Keywords: Children; Children cultures; Television; Teachers. 


\section{INTRODUÇÃO}

Refletir sobre o ser criança no mundo contemporâneo implica, entre outros aspectos, desvelar sua convivência com as mídias e os modos como elas interagem com a cultura televisiva e com as informações que circulam em quantidade e em alta velocidade. Tais relações redimensionam não apenas as interações das crianças entre si, com os adultos, mas também com os conteúdos e formas como vivenciam as suas culturas.

Nesse contexto, observamos que as crianças denotam, em suas culturas e nos modos como se expressam, elementos provenientes dessas mudanças, especialmente no que concerne aos meios de comunicação de massa. Assim, desta interação, origina-se uma geração com profundas transformações nos costumes, hábitos, desejos e necessidades específicas do mundo capitalista de consumo.

Pesquisas como as de Buckingham (2007); Girardello (1999); Pereira (1999); Pinto (2000); 2002); Gómez (1997; 2005); Porto (2000), entre outras, apontam que atualmente os meios de comunicação de massa passaram a ter um espaço-tempo privilegiado no cotidiano das crianças. Segundo dados do Instituto Brasileiro de Geografia e Estatística (IBGE - 2010), 79,5\% das crianças em idade escolar assistem à televisão por duas ou mais horas. Pinto (2000) aponta que, em tese, a criança fica mais tempo em frente ao aparelho televisor do que nas instituições escolares. Excetuando suas horas de sono, esta será, provavelmente, uma das atividades que mais ocupa o tempo no cotidiano das crianças.

Nesse contexto, é evidente que a televisão assuma um importante e relevante espaçotempo no cotidiano das crianças. Conforme ressaltam Filho et al (2011, p. 02), ela "continua sendo um dos principais meios de informação e de entretenimento para a maioria da população brasileira, estimando-se que esteja presente em $98 \%$ das residências brasileiras".

De acordo com Pinto (2000), se considerarmos o binômio criança-televisão à luz de pesquisas realizadas nas últimas décadas sobre essa temática, certamente podemos inferir que os estudos que se preocuparam com o que a televisão faz às crianças são infinitamente mais numerosos do que aqueles que se propuseram a analisar o que elas fazem com a televisão.

Diante do exposto, os estudos que apresentam a relação "crianças e televisão" inevitavelmente levantam questões sobre aspectos culturais e sociais dessa mídia e, também, aspectos sobre a forma como a infância é definida e construída. Tanto a televisão quanto a infância passaram por significativas mudanças nas últimas décadas. A primeira, sobretudo a partir da década de 1980, com mudanças nos aspectos tecnológicos, espaciais e estéticos. Já a infância passou por mudanças, quer em termos das estruturas sociais das famílias e das comunidades, quer em termos de valores, de identidades e de consumo (PEREIRA, 2008).

Ressaltamos, portanto, que refletir sobre as manifestações com conteúdos televisivos na cultura lúdica nas instituições escolares significa problematizar uma importante característica cultural que a geração adulta está disponibilizando às crianças para a sua formação cultural e para a sua vivência em sociedade.

Tomando como base esses apontamentos e compreendendo que há um conjunto de fatores que envolvem, contextualizam, influenciam e determinam a relação crianças e televisão, faz-se necessário, no estudo sobre este binômio, compreender a relação aluno e professor, ou seja, o problema referente à compreensão do professor acerca das culturas infantis com conteúdos televisivos manifestados no contexto pré-escolar.

Nesse sentido, nossa pesquisa partiu do pressuposto de que as crianças manifestam, no contexto escolar, conteúdos e informações decorrentes do contato com as mídias, especialmente as oriundas da televisão e, muitas vezes, esta atividade não é percebida e considerada no contexto escolar. Nessa direção, o nosso objetivo consistiu em verificar as interpretações e visões que as professoras possuíam sobre a relação criança e televisão que são manifestadas no contexto pré-escolar por meio das culturas infantis. 


\section{METODOLOGIA}

Para o desenvolvimento do estudo procurou-se trabalhar num contexto de descoberta, de levantamento e de validação de conhecimentos sobre o tema, muitas vezes, conduzidos por procedimentos intuitivos, maleáveis e adaptáveis à própria evolução do conhecimento sobre o objeto de pesquisa. Pelo fato de a pesquisa qualitativa ser flexível, pois abrange em seu decorrer alguns ajustes e/ou aprofundamentos de natureza teórica e metodológica, selecionou-se o caráter exploratório-descritivo para subsidiar melhor a descrição das características do grupo pesquisado, do contexto e do fenômeno na sua relação com suas distintas variáveis.

Após a sua aprovação pelo Comitê de Ética em Pesquisa da FCT-UNESP, Campus de Presidente Prudente (Protocolo CEP $n^{\circ}$ 5402/2014), a investigação delimitou um determinado espaço social e cultural: uma instituição de Educação Infantil no município de Álvares Machado-SP; e um determinado grupo de sujeitos: professoras de três turmas do Pré I e Pré II.

Diante disso, para que os dados pudessem ser devidamente analisados e interpretados, transformando-se em conhecimentos relevantes para a área, selecionamos a estratégia da pesquisa de caráter do "tipo etnográfico" como abordagem de investigação científica, levando em consideração que as pesquisas nessa perspectiva podem utilizar dos mesmos instrumentos da etnografia, mas com menor permanência do pesquisador no campo de pesquisa. Definido tal procedimento, selecionamos a unidade e o lócus da pesquisa, composto por três professoras e as crianças (4 e 5 anos) de suas respectivas turmas, sendo uma do Pré I e duas do Pré II; e uma instituição de Educação Infantil no município de Álvares Machado, SP.

Em relação aos procedimentos metodológicos, utilizamos as seguintes técnicas: observação participante, entrevistas semiestruturadas com utilização do gravador e diário de campo. Optamos por seguir esse percurso, pois acreditávamos que tais técnicas nos auxiliariam a penetrar na complexidade do problema.

Foram realizadas 100 horas de observações distribuídas em 4 meses do ano letivo de 2015, sendo observado a rotina em sala de aula, momentos de entrada e saídas das crianças e durante os intervalos. O processo de observação foi realizado semanalmente e em dias alternados, para que fosse possível presenciarmos grande parte das atividades programadas na estrutura curricular. Findas as entrevistas, fizemos a transcrição do material de acordo com as falas das professoras e assim, pudemos conhecer um pouco do que as professoras pensam sobre as manifestações de conteúdos televisivos nas culturas infantis pré-escolares.

\section{RESULTADOS}

Através das entrevistas realizadas com as professoras, notamos que em diversos aspectos suas concepções e interpretações assemelham-se ao discurso decorrente que atribui à televisão uma característica que a considera como uma atividade que fomenta atitudes e comportamentos de passividade que impossibilitam às crianças tempo para a realização de outras atividades (PEREIRA, 1999). No polo oposto, em que os discursos têm afirmado que a televisão tem um papel fundamental na formação da criança, especialmente no espaço das novas tecnologias, que entendem a relação criança e televisão como um processo natural e espontâneo; não identificamos entre as professoras visões que apontem para esta mesma perspectiva.

É possível notarmos que as professoras apresentaram uma visão pessimista sobre as transformações da infância e sua relação com a mídia, responsável pelo fim das fronteiras entre o mundo adulto e o mundo infantil. Nessa visão negativa da mídia, as professoras demonstraram se aproximar da tese de que os meios de comunicação, sobretudo a televisão, extinguem as diferenças entre o mundo adulto e o das crianças.

As visões das professoras que defendem a "morte da infância" tendem a definir os telespectadores como uma massa homogênea e as crianças, em particular, como receptores inertes e passivos diante do poder das grandes empresas e dos adultos. Não há um papel atuante, 
segundo elas, para as crianças na ressignificação dos elementos da cultura. Portanto, não há possibilidade de mudança ou intervenção positiva delas sobre a realidade. Cabe aos pais controlar e proteger seus filhos e ajudá-los a resistir à influência da cultura dos meios de comunicação. Nessa perspectiva, os conteúdos televisivos destroem a individualidade e a inocência das crianças, ao menos este é o modo como descrevem o mundo da infância, tendo uma nostalgia do seu próprio passado. Dessa forma, apresentam uma análise pessimista, moralista e desesperada da infância atual (BUCKINGHAM, 2007).

Independentemente das considerações a respeito da natureza transitória da infância, com análises históricas diferenciadas, importa pensarmos as mudanças que ocorreram nas últimas décadas como resultado da amplitude do acesso às mídias, tanto no sentido dos conceitos sobre infância, dominantes atualmente, quanto das experiências vividas pelas crianças no mundo midiático de hoje. Nesse contexto, a infância contemporânea tem uma natureza provisória e diversificada, mudando de modo pouco dramático, porém, contraditório, diferente do que é defendido de um lado e outro, sem uma solução final para essa transformação. Outra questão fundamental é que não podemos abstrair fatores como classes sociais, gênero, etnia e região geográfica, entre outras características sociais.

\section{CONCLUSÃO}

Ao encerrarmos a análise das visões e interpretações das professoras sobre a relação criança e televisão, apresentamos também, amparados em Buckingham (2007) as demais concepções que perpassam o mundo adulto e, por fim, assumimos a concepção crítica como possibilidade de intervenção, posicionamento e mediação no contexto escolar diante da relação crianças e mídias.

A concepção crítica compreende a criança como um sujeito atuante no processo de recepção televisiva que não absorve os conteúdos de maneira passiva, pelo contrário, ressignifica suas apropriações por meio das experiências culturais e sociais. Nessa perspectiva, entende-se que existe espaço para a transformação e para a educação para as mídias.

Nesse sentido, apontamos a necessidade das escolas e dos professores exercerem uma mediação que oriente a aprendizagem dos alunos também fora da sala de aula, de modo que se permita conhecer e contextualizar os conteúdos televisivos sob diversos critérios éticos e sociais. Tal dimensão educativa pode permitir que as crianças, de forma autônoma e crítica, avaliem os conteúdos, pesem os aspectos negativos e positivos e, a partir dessa análise, aproveitem o que de positivo oferecem as mídias. No entanto, vale ressaltar que tal dimensão educativa trata-se de uma formação processual, tanto no que se refere-se a mediação do professor, como na formação da criança mais autônoma e crítica.

Por fim, outro ponto relevante que tratamos foi a formação dos professores no que tange à educação para a mídia. $\mathrm{Na}$ análise dos resultados, ficou latente a carência de um processo formativo propiciador de um diálogo entre teoria e prática, que proporcione procedimentos didáticos coerentes com a meta de uma educação com, para e por meio de mídias. Uma análise cuidadosa dos currículos dos cursos de formação de professores e licenciatura permite-nos depreender que uma educação voltada aos meios de comunicação não é objeto de estudo da maioria deles.

A superação desse problema consiste, então, no desenvolvimento de um processo de formação que, além de dotar o professor de saberes referentes ao conteúdo, permita-lhe estabelecer críticas e/ou manusear com habilidade as diversas tecnologias midiáticas. De acordo com a pesquisa de Borges (2012), uma formação adequada deveria possibilitar ao docente apanhar cada produto midiático em sua concretude histórica, comunicacional, mercadológica, política e também como material que é produzido e veiculado segundo um determinado aparato técnico que, por si mesmo, também produz efeitos em nós. 
A televisão é um bom exemplo dessas possibilidades. De acordo com Pontes (2010), a superação de grande parte dos problemas que afligem a formação de professores não implica simplesmente em uma mera reformulação do curso de Pedagogia, responsável pela formação daqueles que irão atuar na primeira etapa da Educação Básica. Para o autor (2010), o caminho para uma formação mais adequada dos profissionais da educação consiste nas instituições de ensino superior serem mais sensíveis às necessidades das demandas formativas que vêm da escola, sobretudo as escolas públicas, onde as carências são maiores.

A carência de uma formação pedagógica que contemple as novas demandas escolares, como a educação midiática que reivindicamos, torna-se ainda mais exacerbada se considerarmos aquela recebida pelos professores que atuam na Educação Infantil.

Reforça-se e confirma-se nossa conjetura, assumida neste trabalho, de que com professores que sejam capazes de compreender as múltiplas representações da realidade editadas pelas mídias; de estabelecer uma intenção clara em sua prática pedagógica com, para e através desses meios; de planejar e oferecer atividades educativas com a participação ativa dos alunos; que estejam aptos a desenvolver uma prática docente que ressignifique a comunicação escolar restrita, unilateral comumente praticada em sala de aula; pode-se em muito contribuir para a formação, já na Educação Infantil, de sujeitos mais participativos, críticos e com um olhar mais sensível e vivencial para a sociedade tecnológico-midiática ora vivenciada. Descortinam-se, assim, novos horizontes para outras pesquisas sobre e prática pedagógica de professores e uma educação com, para e através das mídias no ambiente educacional.

Diante desses fatores, afirmamos que a escola é um espaço para múltiplas experiências e as crianças são seres que atuam de forma impressionante perante o bombardeio de informações diárias advindas da televisão. Apesar das inúmeras dificuldades da escola pública, é preciso que os conteúdos que compõem o currículo da Educação Infantil incorporem, no seu cerne, a importância de uma educação que suscite nas crianças um espírito crítico e construtivo. Afinal, é nossa responsabilidade política educar para uma civilização melhor no presente e no futuro; para isso, é preciso resgatar, na nossa prática, a utopia de uma educação melhor para as crianças, que valorize o diálogo e que considere os conhecimentos e informações que as crianças trazem das relações estabelecidas além do contexto escolar.

\section{REFERÊNCIAS}

BASTOS, L. A criança diante da TV: um desafio para os pais. Petrópolis: Vozes, 1988, 117p.

BUCKINGHAM, D. Crescer na era das mídias eletrônicas. São Paulo: Loyola, 2007, 301 p.

FILHO, J. B. et al. A programação infantil na televisão aberta: a (des) informação das crianças. Revista Ibero-americana de Educação, 15 mar. 2011. Disponível em: <www.rieoei.org/deloslectores/3224Barros.pdf>. Acesso em: 28 jun. 2011.

GIRARDELLO, G. A imaginação Infantil e as Histórias da TV. In: Primeira Jornada de Debates sobre Mídia e Imaginário Infantil do Curso de Jornalismo e do Pós-Graduação em Educação UFSC, 1999, Santa Catarina. UFSC. Disponível em: <http://www.aurora.ufsc.br/artigos/artigos_imaginacao.htm>. Acesso: 20 mai 2008.

GÓMEZ, G. O. O telespectador frente à televisão. Uma exploração do processo de recepção televisiva. México: Comunicare. Vol.5, no1, 1ㅇs sem 2005.

GÓMEZ, G. O. Professores e meios de comunicação: desafios, estereótipos. Comunicação \& Educação, São Paulo, v. 3, set/dez. 1997, p. 57 - 68 . Disponível em: 
<revcom2.portcom.intercom.org.br/index.php/Comedu/article/.../4078>. Acesso em: $20 \mathrm{mar}$ 2011.

LUDKE, M.; ANDRÉ, M. E. D. A. Pesquisa em Educação: abordagens Qualitativas. São Paulo: EPU, 1986.

MARTÍN-BARBERO, J. Dos meios às mediações: comunicação, cultura e hegemonia. 2. ed. Rio de Janeiro: Ed. UFRJ, 2000.

MUNARIM, I. Brincando na escola: o imaginário midiático na cultura de movimento das crianças. 2007. 194f. Dissertação (Mestrado em Educação) Universidade Federal de Santa Catarina.

Florianópolis.

OROFINO, M. I. Mídias e Mediação Escolar. Pedagogia dos meios, participação e visibilidade. São Paulo: Cortez: Instituto Paulo Freire, 2005. - (Guia da escola cidadã; v.12)

PEREIRA, M. C.; RUARO, L. M. Mídia e desenvolvimento infantil: influências do desenho animado na organização do brincar. 2009. Disponível

em:<http://www.pucpr.br/eventos/educere/educere2009/anais/pdf/2062_1398.pdf>. Acesso em: 03 abr 2011.

PEREIRA, S. Crianças e televisão: convergências e divergências de um campo de estudo. In.: SARMENTO, M.; GOUVEA, M. C. S. (org.) Estudos da Infância: Educação e Práticas Sociais. Petrópolis, RJ: Vozes. 2008.

PEREIRA, S. J. G. A televisão na família - Processos de mediação com crianças em idade préescolar. Portugal: Bezerra. 1999.

PINTO, M. A televisão no cotidiano das crianças. Porto: Afrontamento, 2000, 395 p.

PINTO, M. Televisão, Família e Escola. Editorial Presença: Lisboa. 2002.

PONTES, A. N. A educação das infâncias na sociedade midiática: desafios para a prática docente. 2010. Tese (Doutorado em Educação) Faculdade de Educação da Universidade de São Paulo. Disponível em: <http://www.teses.usp.br/teses/disponiveis/48/48134/tde-24022012-154045/ptbr.php >. Acesso em: 19 Mar 2013

PORTO, T. M. E. A televisão na escola...Afinal, que pedagogia é esta? Porto-Araraquara; JM Editora. 2000, p. 158.

POSTMAN, N. O desaparecimento da infância. Rio de Janeiro: Graphia, 1999.

RICHARDSON, R. J. Pesquisa Social: métodos e técnicas. São Paulo: Atlas, 1989.

SARMENTO, M. J. As culturas da Infância nas Encruzilhadas da Segunda Modernidade. In: SARMENTO, M. J.; CERISARA, A. B. Crianças e Miúdos: perspectivas sociopedagógicas da infância e educação. Edições ASA, 2004.

VIANNA, H. M. Pesquisa em Educação: a observação. Brasília: Plano Editora, 2003. 